\section{Tidal wave with a deaf ear}

Caroline Holland
The General Dental Council (GDC) is NOT an expert educational body, which is a message the Council plans to convey most forcefully during the year ahead. That may be surprising as, for many years, one of its principal roles has been to oversee dental education.

While not giving up on dental education the GDC's emphasis and role has changed dramatically. Until recently, it described itself as having 'statutory responsibility for ensuring high standards of pre-registration and post-registration education for all groups of dental professionals.' Now, the emphasis is that its 'unique contribution and expertise as a regulator should lie in protecting and reflecting public and patient interests and wishes, needs and expectations, and the core values of safety and standards assurance.'

This new ethos belongs to the post-Shipman tidal wave of change and the interests of patients are, quite rightly, preeminent throughout the GDC's work. But there are concerns about the speed of change and lack of pan-dental involvement. A press release published as recently as July 2006 reported on how well the UK's dental schools were performing, announcing: 'UK dental schools are providing sound training for the dentists of tomorrow.' However, an Education Strategic Review Group was then charged with reviewing the Council's education function 'in the light of a modern understanding' of its role. The group's findings were, chiefly: that the emphasis of tion should be favoured, patient focus and professionalism.

Each dental school will be encouraged to devise its own curriculum and course length without the need of GDC approval. No one would have been surprised if it was being mandated that The first five years (TFFY), the GDC's 2002 education document, should be more flexible. Nor that the visitation or inspection panel process was too much of a burden and should end. Both of these changes were predicted in an editorial in the $B D J$ in $2006 .^{2}$ But there is surprise because the change is so radical and:

- There has not been a formal consultation exercise on changes which are of fundamental importance to the profession. Instead, the GDC has held stakeholder workshops which had the aim of 'reaching a mutual understanding of the strategic direction of the GDC in relation to education'

- The eight person review group included four working in dental education but no professor of education

- There has not been more reference to what is happening in dental education should be on outcomes NOT inputs, innova-
Europe, specifically the work of the Association of Dental Education in Europe ${ }^{3}$ which has based some of its recommendations for the competencies of European dentists on TFFY.

Indeed TFFY, a landmark document which benchmarked dental education for the first time, was the starting point in 2003 - following a meeting at the GDC - for developing a commonly agreed core dental curriculum across 23 countries. The GDC might be moving away from TFFY, but, ironically, it lives on in Europe. The Profile and Competencies Document, reviewed by a substantial number of European dental organisations, will be released at the ADEE conference in Helsinki in August . ${ }^{4}$

Another irony is funding. Following the dental schools visitation the inspectors warned that there was 'an urgent need for substantial additional funding if high quality dental training is to be sustained'. Yet the suggestions of the Strategic Education Review Group will inevitably create major resource implications and an administrative burden which an Education Committee minute notes will 'have a substantial backwash

The Dental Schools Council (DSC) has expressed its concerns in a measured way, stating that it has no argument against a patient focused agenda adding: 'but this does need to be balanced with professional opinion, evidence and resource.' For governance reasons the review document, endorsed by the GDC's Education Committee in April 2008, is set in stone and the Education Committee is due to discuss plans next month for its implementation. If the GDC wants the highly-prized commitment of dental school staff to be maintained for the benefit of dentists and DCPs of the future, a thorough communication exercise is imperative. It needs to make up for the lack of consultation thus far and, in the words of the DSC, garner 'professional opinion, evidence and resource.'

1. Education Strategic Review Group: Final report to the Education Committee (24 April 2008)

3. Plasschaert J M, Holbrook W P, Delap E, Martinez C, Walmsley A D. Profile and competences for the European dentist. Eur J Dent Educ 2005: 9: 98-107.

4. Association for Dental Education in Europe. http://www.adee.org (accessed Jan 2009)

DOI: $10.1038 / s j . b d j .2009 .52$ effect on dental schools.'

2. Walmsley A D. GDC visitations - on their way out? Br Dent J 2006; 201 (Suppl): 3 